International Journal of Engineering \& Technology, $7(4.10)(2018) 364-365$
International Journal of Engineering \& Technology
WPC
Website: www.sciencepubco.com/index.php/IJET
Research paper

\title{
A Heuristic Approach to Obtain an Optimal Solution for Unbalanced Transportation Problem
}

\author{
N. Srinivasan ${ }^{1 *}$, A. Seethalakshmy ${ }^{2}$ \\ ${ }^{I}$ Professor, Department of Mathematics, St. Peter's Institute of higher Education and Research, Chennai, India \\ ${ }^{2}$ Assistant Professor, Department of Mathematics, St. Peter's College of Engineering and Technology, Chennai, India \\ *Corresponding author E-mail: sri24455@yahoo.com:
}

\begin{abstract}
This Method is proposed for obtaining an optimal solution for transportation problem. This method gives the optimal solution in lesser iteration. Here find the difference between two consecutive maximum for row-wise and column-wise. In that find the maximum value, for which the minimum is allocated by the minimum supply or demand. Illustration for this method is given with some examples at the end.
\end{abstract}

Keywords: Transportation problems, supply, Demand, Direct method, optimization

\section{Introduction}

Known to be formative methods of linear programming problem is the transportation problem which deals transporting between one point to another, in other words being referred as source and destination. Primary objective of the study is to identify economically viable option which provides the way to transport commodity from source to destination in minimized cost. The caveat here is to be able to maintain the supply and demand requirements. Hitchcock (in 1941) has first developed the transportation problem. This was followed by Charnes, Cooper and many more other authors of with their own algorithms. It can be observed in order to obtain feasible solutions involves two stages, in the former stage basic initial feasible solution and in the latter stage optimal solutions are to be obtained. This study of paper promulgates a new algorithm to determine optimal solution with little iteration without initial basic feasible option. Thereby this method makes it possible to derive solutions in lesser time.

\section{Mathematical form of Transportation Prob- lem}

The transportation problem can be formulated as an LP problem. Let $X_{i j}, \mathrm{i}=1 \ldots . \mathrm{m}, \mathrm{j}=1 \ldots \ldots \mathrm{n}$ be the number of units transported from source $\mathrm{i}$ to destination $\mathrm{j}$.

The LP problem is as follows

Minimize $\mathrm{Z}=\sum_{i=1}^{m} \sum_{j=1}^{n} C_{i j} X_{i j}$

Subject to the constraints

$\sum_{j=1}^{n} X_{i j} \leq S_{i}$ For all i

$\sum_{i=1}^{m} X_{i j} \geq d_{j}$ For all $\mathrm{j}$

$X_{i j} \geq 0$

A transportation problem is said to be balanced if

$\sum_{i=1}^{m} S_{i}=\sum_{j=1}^{n} d_{j}$

\section{Algorithm}

Step 1

For the given data construct a transportation table. If the problem is unbalanced make it as a balanced one.

Step 2

Subtract the smallest element from each row to all other elements in that row.

Step 3

Subtract the smallest element from each column to all other elements in that column.

Step 4

For all the zeros present in the matrix and the total sum of rows and columns. In that pick the maximum value and allocate

Minimum supply/demand to that cell .The row and column of that element where the supply/demand is satisfied is deleted.

Step 5

If the maximum value is repeated many times ,then zero which has minimum supply/demand can be allocated.

Step 6

Till all the supply and demand get exhausted the process is repeated from steps 2 and 4.

Step 7

The total minimum cost is calculated by

Total cost $=\sum_{\mathrm{i}=1}^{\mathrm{n}} \sum_{\mathrm{j}=1}^{\mathrm{n}} \mathrm{C}_{\mathrm{ij}} \mathrm{X}_{\mathrm{ij}}$

\section{Numerical Examples}

\section{Example 4.1}

A company has three factories and four distribution centers.

Table 1: Data Table for the Problem 


\begin{tabular}{|c|c|c|c|c|c|}
\hline \multirow{6}{*}{ 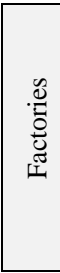 } & & \multicolumn{3}{|c|}{ Distribution } & Supply \\
\hline & & A & $\mathrm{B}$ & $\mathrm{C}$ & \\
\hline & $S_{1}$ & 6 & 10 & 14 & 50 \\
\hline & $S_{2}$ & 12 & 19 & 21 & 50 \\
\hline & $S_{3}$ & 12 & 15 & 17 & 50 \\
\hline & Req. & 30 & 40 & 55 & \\
\hline
\end{tabular}

Find the minimum transportation cost.

Step 1:

The given problem is unbalanced. Make it balanced by adding the dummy column with zero as entries.

Table 2: Balanced Data Table for the Problem

\begin{tabular}{|c|c|c|c|c|c|c|}
\hline \multirow{6}{*}{$\frac{\tilde{U}}{\stackrel{\tilde{\Xi}}{0}}$} & & \multicolumn{4}{|c|}{ Distribution } & Supply \\
\hline & & A & $\mathrm{B}$ & $\mathrm{C}$ & $\mathrm{D}$ & \\
\hline & $S_{1}$ & 6 & 10 & 14 & 0 & 50 \\
\hline & $S_{2}$ & 12 & 19 & 21 & 0 & 50 \\
\hline & $S_{3}$ & 12 & 15 & 17 & 0 & 50 \\
\hline & Req. & 30 & 40 & 55 & 25 & \\
\hline
\end{tabular}

Step 2:

Table 3: First Iteration for the given Problem

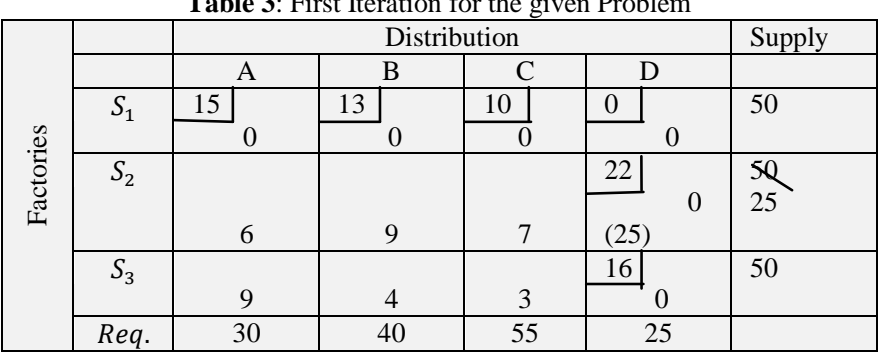

In the above table for the entire zeros the sum of row and column is calculated and written in the left corner. In that the maximum value 22 is got allocated with minimum supply/demand 25. Delete the column D since the supply is exhausted.

Step 3:

Table 4: Second Iteration for the given Problem

\begin{tabular}{|c|c|c|c|c|c|c|c|}
\hline \multirow{8}{*}{ 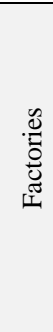 } & & \multicolumn{5}{|c|}{ Distribution } & Supply \\
\hline & & $\mathrm{A}$ & \multicolumn{2}{|c|}{ B } & \multicolumn{2}{|r|}{$\mathrm{C}$} & \\
\hline & \multirow[t]{2}{*}{$S_{1}$} & \multirow[b]{2}{*}{0} & 4 & 0 & \multirow{2}{*}{\multicolumn{2}{|c|}{1}} & \multirow[t]{2}{*}{50} \\
\hline & & & & & & & \\
\hline & \multirow[t]{2}{*}{$S_{2}$} & & \multirow{2}{*}{\multicolumn{2}{|c|}{3}} & \multirow{2}{*}{\multicolumn{2}{|c|}{1}} & \multirow[b]{2}{*}{25} \\
\hline & & & & & & & \\
\hline & $S_{3}$ & 6 & & 1 & \multicolumn{2}{|r|}{0} & 50 \\
\hline & Req. & $30 \quad 5$ & & 40 & & 55 & \\
\hline
\end{tabular}

Step 4:

Table 5: Final Iteration for the given Problem

\begin{tabular}{|c|c|c|c|c|c|}
\hline \multirow{5}{*}{ : } & & \multicolumn{3}{|c|}{ Distribution } & Supply \\
\hline & & A & $\mathrm{B}$ & $\mathrm{C}$ & \\
\hline & $S_{1}$ & $\begin{array}{l}0 \\
(5)\end{array}$ & \begin{tabular}{l|l}
1 & \\
& 0 \\
& $(40)$ \\
\end{tabular} & \begin{tabular}{c|l}
0 & \\
- & 0 \\
& $(5)$
\end{tabular} & 50 \\
\hline & $S_{3}$ & 6 & 1 & \begin{tabular}{l|l}
7 & \\
- & 0 \\
& $(50)$
\end{tabular} & 50 \\
\hline & Req. & $30 \quad 5$ & 40 & 55 & \\
\hline
\end{tabular}

Step 5:

Table 6: Cell Allocation for the given Problem

\begin{tabular}{|c|c|c|c|c|c|}
\hline \multirow{2}{*}{ 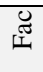 } & \multicolumn{4}{|c|}{ Distribution } & Supply \\
\hline & A & $\mathrm{B}$ & $\mathrm{C}$ & $\mathrm{D}$ & \\
\hline
\end{tabular}

\begin{tabular}{|c|c|c|c|c|c|}
\hline$S_{1}$ & $\begin{array}{c}6 \\
(5)\end{array}$ & $\begin{array}{c}10 \\
(40)\end{array}$ & $\begin{array}{c}14 \\
(5)\end{array}$ & 0 & 50 \\
\hline$S_{2}$ & $\begin{array}{c}12 \\
(25)\end{array}$ & 19 & 21 & $\begin{array}{c}0 \\
(25)\end{array}$ & 50 \\
\hline$S_{3}$ & 12 & 15 & $\begin{array}{c}17 \\
(50)\end{array}$ & 0 & 50 \\
\hline Req. & 30 & 40 & 55 & 25 & \\
\hline
\end{tabular}

Minimum cost $=6 \times 5+10 \times 40+14 \times 5+12 \times 25+0 \times 25+$ $17 \times 50$

Minimum cost $=1650$

\section{Conclusion}

The direct method towards solving transportation problem is dealt in this research paper. This research work is applicable for all of its kind. This is a methodical way of providing an efficient solution in fewer steps, in addition this method is similar to MODI method where the degeneracy does not occurs. Salient feature of this method is in its advantage of less time taken in reaching the objective of this method. As a result we propose this method to be a unique solution to the problem previously thus developed.

\section{References}

[1] H.A.Taha, operations research-Introduction, prentince hall of India New Delhi, 8th edition 2007.

[2] K.Sharma, operations Research-Theory and application,Macmillian India LTD,New Delhi-2005.

[3] P.K.Gupta ,D.S hira,operation Research, S. Chand \& Company Limited,14th Edition 1999.

[4] N.Srinivasan, D.Iraninan, A new approach for solving assignment problem with optimal solution, International journal of Engineering and management research,Volume 6 Issue 3 may June 2016.

[5] A.Thirupathi, D.Iraninan, An innovative method for finding optimal solution to assignment problems, International journal of Innovative Research in Science, Engineering and Technology, Vol 6,Issue 8,August 2015.

[6] Shweta Singh.G.C.Dubey,Rajesh Shrivastava-Compararative analysis of Assignment problem, Vol 2,Issue 8 (Aug 2012) Pp 1-15.

[7] M.Wali Ullah,M.Alhaz Uddin and Rijwana Kawser,A Modifed Vogels Approximation Method for Obtaining a good primal solution of Transportation Problems,Annals of Pure and Applied Mathematics,Vol.11.No.1,2016,63-71.

[8] S.Rekha,B.Srividhya and S.Vidya,Transportation Cost Minimization: Max Min Penalty Approach,,IOSR Journal of Mathematics(IOSR-JM),Vol. 10,Issue 2 ,(Mar-Apr.2014),PP 6-8

[9] P.Pandian and G.NatarajanA New method for finding an optimal solution for transportation problem,IJMSEA, Vol 4, pp 59-65,2010.

[10] Abdul Sattar Soomru,Muhammad Junaid,Gurudev Anand Tularam, Modi_ed Vogels Approximation Method for Solving Transportation Problems,Mathematical Theory and Modelling,Vol. 5, No.4,2015

[11] A. Seethalakshmy, N. Srinivasan, Solving Assignment Problem to get an Optimal Solution using Zero Reduction Method, Global Journal of Pure and Applied Mathematics, Volume 13, Number 1 (2017).

[12] A. Seethalakshmy, N. Srinivasan, A New Approach to obtain an Optimal Solution for The Unbalanced Assignment Problem, International Journal of Pure and Applied Mathematics, Volume 114 No. 62017,77 - 85.

[13] A.Seethalakshmy, N. Srinivasan, A New Approach to Obtain an Optimal Solution for the Assignment Problem, International Journal of Science and Research, Volume 5 ,Issue 10,October 2016.

[14] ElsiddigIdriss Mohamed Idriss, Elfarazdag Mahjoub, Mohamed Hussein, Application of linear programming (AssignmentModel), International Journal of Science and Research(IJSR),ISSN 2319. 7064 . 